\title{
Effects of Graphene Oxide on the Conductivity and Capacitance of Polypyrrole
}

\author{
Changjing $\mathrm{Fu}^{2}$, Qiang Ma ${ }^{1, *}$, Hongfan Liu ${ }^{1}$, Wenyan Tang ${ }^{1}$ \\ ${ }^{1}$ School of Electrical Engineering \& Automation, Harbin Institute of Technology, Harbin 150001, \\ P.R.China \\ ${ }^{2}$ School of Materials Science \& Engineering, Heilongjiang University of Science \& Technology, \\ Harbin 150022, P.R. China \\ *E-mail: qiangma@ hit.edu.cn
}

doi: $10.20964 / 2018.05 .42$

Received: 5 January 2018 / Accepted: 28 February 2018 / Published: 10 April 2018

\begin{abstract}
A polypyrrole and graphene oxide (PPy/GO) composite was synthesized by a chemical in situ polymerization method at low temperature to modify and improve the dispersibility and conductivity of polypyrrole. Graphene oxide was prepared by the modified Hummers' method. The phase composition, microstructure, conductivity and capacitance of the composite were characterized and measured using XRD, SEM, a source meter and an electrochemical workstation, respectively. The results showed that pyrrole could evenly cover the surface of GO due to the oxygen-containing functional groups on the surface and edges of GO. The highest conductivity the composite achieved was 27 times higher than that of PPy. The specific capacitance of the composite remained at $389 \mathrm{~F} \cdot \mathrm{g}^{-1}$ under a current density of $2 \mathrm{~A} \cdot \mathrm{g}^{-1}$ after 1000 cycles, and the capacitance loss was only $3.47 \%$, which exhibited that the PPy/GO composite had a high specific capacitance and good cycle stability as an electrode material for supercapacitors.
\end{abstract}

Keywords: Polypyrrole, Graphene oxide, In situ polymerization, Capacitance

\section{FULL TEXT}

(C) 2018 The Authors. Published by ESG (www.electrochemsci.org). This article is an open access article distributed under the terms and conditions of the Creative Commons Attribution license (http://creativecommons.org/licenses/by/4.0/). 